\title{
O CONTO MACHADIANO ENTRE A TRADUÇÃO, A CIRCULAÇÃO CULTURAL E AS NOVAS CONSTRUÇÕES CONCEITUAIS
}

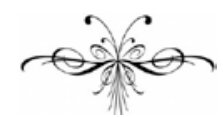 \\ BETHANIA GUERRA DE LEMOS
}

Resumo: A partir de reflexões sobre a obra contística e o pensamento de Machado de Assis, propomos estabelecer relações entre a tradução, entendida como estratégia de mediação e difusão cultural, e a construção de um conceito amplo de literaturas latino-americanas. Como parte desse projeto de tradução e pesquisa, apresentamos ainda uma antologia de 30 contos machadianos traduzidos para o espanhol e publicados no ano de 2011, em Valência/ Espanha.

Palavras-chave: Machado de Assis; literatura latino-americana; tradução; contos.

\begin{abstract}
By analyzing Machado de Assis's short stories work and thought, we intend to point out relationships between translation, here understood as a mediation and cultural diffusion strategy, and the building of a broad concept of Latin American literatures. We also present an anthology of 30 short stories by Machado de Assis translated into Spanish and published in 2011 in Valencia/Spain, as part of this translation and research project.
\end{abstract}

Keywords: Machado de Assis; Latin American literature; translation; short stories.

\section{Tradução e internacionalização}

$\mathrm{O}$ presente artigo se configura como uma breve reflexão, a partir da obra contística e do pensamento de Machado de Assis, sobre as relações entre a tradução e a construção de um conceito amplo de literatura latino-americana. Para tal tarefa, consideramos o exercício de traduzir e publicar traduções como estratégias de mediação e difusão cultural, que não só são capazes de ampliar o capital literário dos leitores potenciais, mas também de contribuir para o estabelecimento de novas maneiras de entender os territórios e suas representações artísticas. 
De acordo com Antonio Cornejo Polar (2000), escritor peruano e um dos principais pensadores sobre o desenvolvimento de uma nova conceituação da história literária na América Latina, as culturas são uma totalidade contraditória, porém com seus diferentes setores em íntima e profunda relação. O grande desafio para a historiografia latino-americana seria encontrar a forma de aproximar-se da dualidade entre tradição e modernidade, passado e futuro, mito e renovação. De acordo com essa visão, a literatura e a arte em geral são elementos formadores da memória histórica dos povos, que se entrecruzam representando ao mesmo tempo um passado mítico e um presente/futuro de negociações possíveis.

Nossa primeira observação nesse sentido, é que a defesa do mesmo processo, em outros termos, é encontrada um século antes nas obras ficcionais e trabalhos críticos machadianos, como o emblemático texto "Instinto de nacionalidade". Machado acreditava que a leitura e a tradução exerciam papéis fundamentais de mediação cultural no processo de construção de una estética. O tradutor é visto como o leitor privilegiado, que traduz não só palavras, mas também culturas, recria através da retórica e pode convencer - ou não - sobre a validade do novo relato.

Para Machado de Assis, a tradução era um elo fundamental na corrente das relações culturais, sendo uma das maneiras de colocar em diálogo diferentes línguas e culturas, e de enriquecer a sua própria tarefa de escritor a partir de um aspecto fundamental na construção da identidade brasileira. Desta forma, aproximou-se da tradução como leitor e tradutor. De acordo com Ferreira (2004, p. 34), em Para traduzir o século XIX: Machado de Assis:

Esse ponto de vista machadiano pode ser relacionado com o conceito de "comércio intelectual geral", "um mercado onde todas as nações oferecem seus bens", criado por Goethe, que propiciaria o intercâmbio das ideias, no qual a tradução exerceria um papel crucial, pois para o poeta alemão, segundo Pascale Casanova (2002:28), o tradutor era visto como "um ator central desse universo", não somente como intermediário, mas igualmente como criador de "valor literário".

O movimento de Machado de Assis em direção à internacionalização de sua obra pode ser entendido em duas vertentes: o empenho por fazer com que seus livros circulassem em Portugal e as tentativas de fomentar as traduções de sua obra (Guimarães, 2010: 164). Como se sabe, os três primeiros importantes esforços de tradução de obras em vida do autor foram para a língua alemã, nos quais ele se envolveu diretamente, sem conseguir, entretanto, o apoio de Garnier, seu editor. O primeiro deu-se em 1882, o segundo em 1888 e o terceiro em 1889.

Existe também um registro de tentativa de tradução para o francês, em 1901, com intervenção de Machado e correspondência entre o possível tradutor e o escritor, esforço que também não deu frutos. A primeira tradução de uma obra sua ao francês é

\footnotetext{
${ }^{1} \mathrm{O}$ ensaio “Instinto de nacionalidade”, publicado em 24 de março de 1873 foi encomendado pela revista O novo mundo (Nova York, 1870-1879), e publicado pela primeira vez em Nova York em língua portuguesa. Esse periódico é hoje em dia uma das fontes fundamentais para o estudo da formação da literatura brasileira, e o fato de que tenha sido editado em outro país é muito significativo. A revista não tratava somente temas relacionados com o Brasil, mas vários de seus artigos dedicaram-se a diferentes áreas da cultura norte-americana e europeia. Foi uma publicação de grande importância naquele momento, que lançou novos nomes da literatura brasileira e portuguesa e que refletiu sobre a literatura universal.
} 
do ano de 1910, em uma coleção parisiense de contos realizada por Adrien Delpeche, que também traduziu, um ano mais tarde, Memórias póstumas de Brás Cubas (Guimarães, 2010, p. 168 e Rocca, 2010). As duas únicas obras de Machado de Assis que contaram com traduções publicadas durante a vida do autor foram Memórias Póstumas de Brás Cubas e Esaú e Jacó, para a língua espanhola. Machado não se envolveu nestas traduções como nas anteriores tentativas frustradas, mas demonstrou, sem dúvida, "simpatia e apreço" pelos trabalhos.

O outro movimento, antes citado, foi o esforço para que seus livros tivessem maior recepção em Portugal. De acordo com Guimarães (2010, p. 169):

Trata-se do mercado português, este, sim, em acirrada concorrência com o mercado brasileiro de livros, como demonstraram as tensas relações entre escritores, críticos e livreiros de ambos os países, que durante o século XIX trocavam acusações de avanços indevidos em direção ao público ou mesmo ao espaço ficcional de um ou outro país.

Tais conflitos, não isentos de questões políticas e culturais, já que nesse momento se delineava uma maior construção de valores nacionais no Brasil, afetavam profundamente a circulação das obras entre os dois países. Em 1887 o autor empreendeu esforços semelhantes aos anteriores, sem sucesso, na tentativa de que alguma obra sua contasse com uma publicação portuguesa. A recepção da obra de Machado em Portugal foi sempre irregular. O autor foi, inclusive, mais conhecido no país como poeta e dramaturgo do que como narrador, sendo a narrativa, como se sabe, a parte mais ampla de toda a sua produção.

\section{Estética fundacional para a América Latina}

As ideias machadianas sobre a circulação de obras, o diálogo entre autores e idiomas, as influências e a tradução como mediação e difusão editorial, ficam claras tanto em sua trajetória vital quanto em seus textos ensaísticos. Entretanto, também no campo ficcional, e em especial em seus contos, o autor revela estes pensamentos, através da construção de um território de fragmentos, de olhares agudos, oblíquos e dialogantes, que sacodem a alma humana na busca do outro: estranho e familiar.

Por exemplo, o reflexo sobre a superfície embaçada que reproduz medos e temores e aparece em “O espelho” será encontrado no século XX nos relatos de Jorge Luis Borges: a imagem labiríntica e duplicada que revela terríveis lutas internas com esse outro que sou $e u$. Em "A causa secreta" outros venenos da alma humana são trazidos à tona, o que a princípio poderia ser simplesmente o retrato de um personagem exagerado e peculiar, conduz o leitor a um argumento de fundo complexo e cruel. A influência de Poe e os aspectos que anunciam temas que veríamos mais adiante no tempo e em outros espaços (como nos Cuentos de amor de locura y de muerte de Horacio Quiroga) são evidentes.

Portanto, como parte da construção de uma identidade literária para a América Latina, a figura de Machado de Assis representa muito mais que o principal escritor brasileiro do século XIX. É um dos mais importantes fundadores do conto moderno em toda a América de língua espanhola e portuguesa; pela inovação de suas técnicas, pela maturidade de sua narrativa e por aspectos cronológicos inegáveis. Só precisamos nos lembrar de que quando lança seu terceiro volume de relatos, em 1882, autores como Tchekhov ou Maupassant começavam a publicar seus primeiros; e na 
América Latina praticamente toda a obra contística de Machado é anterior aos primeiros livros de Quiroga.

A nova literatura nacional defendida por Machado de Assis (1959, p. 32-33) e desenvolvida em toda sua obra, passa pela compreensão da necessidade da incorporação dos elementos diferentes e díspares formadores do povo brasileiro e por extensão, latino-americano. E, ao mesmo tempo, pela realização de um movimento em direção à universalidade, à literatura mundial, processo dentro do qual a leitura e a tradução ocupam um papel fundamental de mediação entre culturas:

[...] Devo acrescentar que neste ponto manifesta-se às vezes uma opinião, que tenho por errônea: é a que só reconhece espírito nacional nas obras que tratam de assunto local, doutrina que, a ser exata, limitaria muito os cabedais da nossa literatura. Gonçalves Dias, por exemplo, com poesias próprias, seria admitido no panteão nacional; se excetuarmos Os Timbiras, os outros poemas americanos e certo número de composições, pertencem os seus versos pelo assunto a toda humanidade, cujas aspirações, entusiasmo, fraquezas e dores geralmente cantam; [...] Mas, pois que isto vai ser impresso em terra americana e inglesa, perguntarei simplesmente se o autor do Song of Hiawatha não é o mesmo autor da Golden Legend, que nada tem com a terra que o viu nascer, e cujo cantor admirável é; e perguntarei mais se o Hamlet, o Otelo, o Júlio César, a Julieta e Romeu têm alguma coisa com a história inglesa nem com o território britânico, e se, entretanto, Shakespeare não é, além de um gênio universal, um poeta essencialmente inglês. Não há dúvida que uma literatura, sobretudo uma literatura nascente, deve principalmente alimentar-se dos assuntos que lhe oferece a sua região, mas não estabeleçamos doutrinas tão absolutas que a empobreçam.

Todos os esforços e movimentos do autor por difundir o pensamento estético brasileiro e a criação literária do país, colocando-os em relação com a produção mundial da sua época, confluem em um projeto amplo de um "instinto de nacionalidade” muito diferente de um nacionalismo limitador de fronteiras.

A escrita de una literatura nacional passa também por restabelecer novas formas de criação, nesse aspecto Machado de Assis coloca a literatura brasileira em um nível muito alto, com sua estética fina, irônica, plena de intertextualidades e de estruturas inovadoras. $\mathrm{O}$ fato de que a maioria de seus contos esteja ambientada no Rio de Janeiro não faz com que estes sejam menos universais. Como se observa, por exemplo, no conto "Uma visita de Alcibíades". O autor lança mão de vários procedimentos retóricos com maestria, na construção de um relato que, além de peça ficcional, pode ser lido também como um manifesto que transcende fronteiras e épocas, e aponta importantes bases da estética machadiana.

Incluído na obra Papéis avulsos (1882), o relato é um texto central no qual Machado trabalha ficcionalmente aspectos fundamentais de sua obra: o encontro entre o clássico e o moderno; a discussão estética; a importância da tradição na conformação da modernidade; a metaliteratura (a construção do discurso funciona como estratégia para a elaboração do próprio argumento da narração); e a mistura do universal com os elementos locais. Também destacamos a importância dos procedimentos retóricos utilizados pelo autor na representação literária e as inovações que propõe ao conto moderno do século XIX.

O relato surpreende pelo insólito de sua trama e de sua conclusão: como se sabe, coincidem em um quarto, através do espiritismo, um personagem da Grécia clássica e um cidadão brasileiro do século XIX. A partir dessa cena inicial se 
desencadeia una animada conversa que, com o humor e a ironia como protagonistas, faz avançar o relato. Tudo é contado através de una carta, recriando o gênero epistolar e ampliando as fronteiras do conto moderno na América Latina. A perspectiva é claramente fantástica, anunciando o subgênero que seria desenvolvido plenamente no século XX.

Mesmo sem ter escrito um decálogo do perfeito contista como o de Quiroga (1928), estabelecido conceitos como Todorov (1970), rastreado os aspectos do conto como Cortázar (1971), ou redigido umas teses como as de Piglia (1986), entre tantas outras importantes teorias, Machado de Assis deixou um legado de modelo estético que se recupera em suas obras ficcionais e ensaios gerais, e que, em muitos aspectos, anuncia as observações desses autores futuros.

Em “Uma visita de Alcibíades” as suas convicções expressadas em ensaios como "Instinto de nacionalidade" aparecem sob a roupagem dos personagens. O ilustre ateniense morre duas vezes, uma em sua história já conhecida, e outra na nova história construída a partir de elementos fantásticos. A segunda morte é inevitável, já que entram em choque os sistemas estéticos da Grécia clássica e do realismo do século XIX. Entretanto, nessa morte é possível ver múltiplos elementos: a ironia machadiana opera no conto no sentido de crítica aos que negam taxativamente o passado, e, por outro lado, também se pode ver uma defesa da necessidade de forjar una nova escrita.

\section{Morte e vida de Alcibíades em espanhol}

Até o ano de 2011, contos como o emblemático "Uma visita de Alcibíades” ou "Último capítulo" nunca haviam sido publicados em língua espanhola. Sendo assim, um projeto que desejasse contribuir com a reconfiguração do conceito inclusivo de literatura latino-americana, além da circulação e a difusão de peças fundamentais para o conhecimento da estética machadiana e de seu caráter precursor, não poderia ignorar esta lacuna.

Com este panorama como ponto de partida, dois tradutores, Juan Bautista Rodríguez Aguilar e Bethania Guerra de Lemos, elaboram e apresentam à editora espanhola Pre-Textos, em 2009, um projeto em colaboração. Tal proposta constava da seleção e tradução de 30 relatos representativos da fase de maturidade do escritor, redação de notas e de um prólogo crítico, com o objetivo de contribuir com a tarefa de responder à lacuna literária e cultural referente à difusão dos contos de Machado em terras hispânicas. O trabalho foi desenvolvido ao longo dos anos de 2010 e 2011, culminando com sua publicação na coleção "Narrativa Clásicos” da editora citada em maio de $2011^{2}$, com o apoio do Programa de Tradução de autores brasileiros no exterior, da Fundação Biblioteca Nacional do Brasil.

O resultado constitui, até o momento, a maior antologia de contos de Machado de Assis em língua espanhola, considerando o número de relatos disponível em suporte físico. A única edição com o mesmo número é de 1978, do tradutor Santiago Kovadloff, para a importante editora venezuelana Biblioteca Ayacucho, disponível atualmente em suporte digital. A edição de Kovadloff é de inegável importância e valor; entretanto, acreditamos que era necessário apresentar uma nova proposta de tradução, com um tratamento especial nas notas, na adaptação ao

\footnotetext{
${ }^{2}$ A editora Pre-Textos, com sede em Valencia/Espanha, conta também com ampla distribuição na Argentina, México, Colombia e Chile.
} 
castelhano e critérios de tradução atuais, sempre com um profundo cuidado ao tratar o estilo do autor.

Além dos citados anteriormente, outros relatos inéditos em espanhol são apresentados na edição: "Na arca”, "Singular ocorrência”, "Uma senhora”, "Primas de Sapucaia!”, “A segunda vida” e "Conto de escola”. O critério foi o de selecionar trinta contos representativos de seu período de maturidade e maior fecundidade, marcado tradicionalmente pelo ano de 1881, com a publicação de Memórias póstumas de Brás Cubas. Todas as peças escolhidas pertencem a antologias publicadas pelo autor posteriormente a 1881, com exceção do primeiro, “O Machete”, publicado em 1878 no Jornal das Famílias.

A nova edição se insere, desta forma, em um projeto acadêmico maior ${ }^{3}$, de pesquisa e reconfiguração conceitual do qual tratamos no presente artigo. Pretendemos que a antologia Cuentos de madurez seja um primeiro passo para futuras traduções de outros relatos machadianos ainda inéditos em castelhano. Acreditamos que, como se afirma neste trabalho, a tradução é uma das portas de mediação cultural que precisa ser aberta e fomentada para que tal projeto siga em frente.

A literatura brasileira foi poucas vezes realmente estudada como parte integrante das manifestações artísticas latino-americanas. Embora a expressão se utilize frequentemente, o termo literatura latino-americana é aplicado de maneira muito incipiente com a inclusão do Brasil, que sempre, ou quase sempre, é visto como um espaço cultural afastado dos demais países da América Latina, hispano-falantes. Cremos que é possível, e mais ainda, necessário, retomar ou inaugurar, junto a outros pesquisadores, tradutores e professores que trabalham hoje na mesma linha, um olhar abrangente, que traga ao primeiro plano um território amplo, diverso, porém intimamente ligado dentro de sua heterogeneidade, como é o da América Latina.

A contística de Machado de Assis, fundadora do gênero no Brasil, também o é nesse imenso continente literário, que fala português, espanhol, francês, inglês, e centenas de línguas indígenas. Um território que não precisa criar espaços de exclusão cultural, e sim de diálogo, já que suas trajetórias históricas, políticas e literárias dialogam há muito tempo em vários aspectos. Retomando a ideia das culturas latinoamericanas que se constroem em um entorno histórico e atual de hibridação, entendemos tal estado como um processo, mas também uma condição que permite observar o passado e pensar nas lógicas de produção cultural no presente. Uma nova compreensão do capital cultural herdado e acumulado pela memória histórica é fundamental, já que este, frente às novas condições de existência, se transforma e propõe combinações simbólicas que podem atuar como formas de resolver ou entender os conflitos de ordem social, econômica e cultural, configurando-se como o que o argentino García Canclini denomina negociações, e que o escritor mexicano Octavio Paz apresentava como processo ou elemento híbrido.

Sendo assim, o híbrido cultural é o resultado do conflito entre forças sociais mediatizadas através de um processo de ressimbolização. Tal enfoque é o que nos permite compreender o clássico e o popular, o local e o universal (como queria Machado de Assis), o original e as traduções, como partes fundamentais de una mesma partitura de circulação, recepção e criação artística. Qualquer tipo de maniqueísmo se apresenta insatisfatório como explicação dos processos sociais e

\footnotetext{
${ }^{3}$ Durante o ano acadêmico 2010-2011 desenvolvi na Universidad Autónoma de Madrid uma pesquisa sobre a fundação do conto latino-americano, vinculada ao departamento de Filología Hispánica.
} 
culturais, já que a delimitação de territórios simétricos é cada vez mais complexa e o hibridismo é uma das marcas históricas das culturas latino-americanas, desde a sua formação. A possível eficácia desse movimento estará na sua capacidade de representar o que as interações culturais têm de oblíquo e dissimulado (adjetivos preferidos por Machado de Assis para definir seus personagens em romances e contos), permitindo repensar os vínculos entre cultura e poder, que, sem dúvida, não são verticais.

O contexto social urbano latino-americano é também híbrido, às vezes ambíguo e contraditório, porque todas as tradições que o formam são também fronteiriças, pertencentes a diferentes universos culturais. A urbe do século XIX que surge nos contos de Machado, "moderna" em muitos aspectos e antimoderna em outros, na qual se misturam o passado colonial, os escravos, a corte portuguesa com o luxo e as inovações europeias, é o território fértil, no qual tudo está presente, e se configura como cenário para os relatos. Dessa forma, o trabalho de tradução realizado em paralelo com as pesquisas sobre o pensamento do autor e a forma de seus contos, se integra em um projeto que tem como objetivo relacionar e fomentar o diálogo e as interseções da obra machadiana com o mundo hispânico.

Bethania Guerra de Lemos

bethaniaguerra@tufts-skidmore.es

Tufts University in Madrid

\section{Referências}

ASSIS, Joaquim Maria Machado de. Cuentos de madurez. Edición, traducción y prólogo de Bethania Guerra de Lemos y Juan Bautista Rodríguez. Valencia: Pre-textos, 2011.

. Obra completa. Edição comemorativa dos 100 anos de morte do autor. Quatro volumes. Rio de Janeiro: Nova Fronteira, 2008.

. Cuentos. Selección y prólogo Alfredo Bosi. Traducción Santiago Kovadloff y Margara Russotto. Caracas: Biblioteca Ayacucho, 1988.

. [1873] "Instinto de nacionalidade” in: Machado de Assis: crítica, notícia da atual literatura brasileira. São Paulo: Agir, 1959. p. 28 - 34.

CORNEJO POLAR, Antonio. O condor voa. Literatura e Cultura Latino-Americanas Org. Maria J. Valdés. Trad. Ilka Valle de Carvalho. Belo Horizonte: UFMG, 2000.

CORTÁZAR, Julio. “Algunos aspectos del cuento” Cuadernos Hispanoamericanos, núm. 25, Madrid: AECID, marzo 1971, pp. 403-406.

FERREIRA, Eliane. F. C. Para traduzir o século XIX: Machado de Assis. São Paulo: Annablume; Rio de Janeiro: Academia Brasileira de Letras, 2004.

GARCÍA CANCLINI, Néstor. Culturas Híbridas. Estratégias para entrar e sair da modernidade. Trad. Ana Regina Lessa, Heloisa Pezza Cintrão. São Paulo: Edusp, 2000. 
GUIMARÃES, Hélio de Seixas. "Uma vocação em busca de línguas: notas sobre as (não) traduções de Machado de Assis” in: FANTINI, Marli (org.). Machado e Rosa. Leituras críticas. Cotia, SP: Ateliê Editorial, 2010, pp. 163-171.

PAZ, Octavio. Los hijos del limo. Barcelona: Seix Barral, 1989.

PLIGIA, Ricardo. “Tesis sobre el cuento" [1986], in: Formas breves. Barcelona: Anagrama, 2000.

QUIROGA, Horacio. “Decálogo del buen contista” [1928], in: Cuentos. Caracas: Biblioteca Ayucucho, 2004.

ROCCA, Pablo. "Machado de Assis, escritor do Rio da Prata: duas hipóteses contraditórias" in: FANTINI, Marli (org.). Machado e Rosa. Leituras críticas. Cotia, SP: Ateliê Editorial, 2010, pp. 283- 295.

TODOROV, Tveztan. [1970] Introducción a la literatura fantástica. Trad. Silvia Delpy. México: Premia, 1981. 